\title{
Quem iria votar? \\ Conhecendo as conseqüências do voto obrigatório no Brasil
}

\begin{tabular}{c}
\hline \hline Zachary Elkins \\
Departament of Political Science \\
University of California, Berkeley \\
\hline \hline
\end{tabular}

\begin{abstract}
Resumo
O artigo enfoca a importância do voto obrigatório para a democracia brasileira. Através da análise de dados de surveys realizados antes das eleições presidenciais de 1994 e 1998, o artigo dimensiona as conseqüências da abolição do voto obrigatório em termos da igualdade da participação em grupos demográficos e políticos de eleitores.
\end{abstract}

Palavras-chave: voto obrigatório, eleição presidencial, comportamento político, Brasil.

\section{Abstract}

The article focus on the importance of the mandatory voting for the Brazilian democracy. By analysing data from surveys conducted before the presidential elections in 1994 and 1998, the article assesses the consequences of abolishing the compulsory voting in terms of the equality of participation across a number of demographic and political groups of Brazilian voters.

Key words: mandatory voting, presidential election, political behavior, Brazil. 


\section{Introdução}

No Brasil, $5 \%$ dos brasileiros pagam impostos, enquanto mais de $80 \%$ votam. A mais comum explicação desse paradoxo (ao menos para a sua segunda metade) é que os cidadãos brasileiros alfabetizados com idade entre 18 e 70 anos são obrigados a votar. Os analistas, tanto os que condenam (Bollen, 1980) quanto os que apoiam (Lijphart, $1995 \mathrm{e}$ 1997), concordam que o voto obrigatório geralmente aumenta o comparecimento em por volta de 25 pontos (ver Jackman, 1987). Essa estimativa acompanha outros estudos sobre comparecimento que demonstram que as regras e procedimentos eleitorais têm um impacto considerável na decisão de votar (Wolfinger and Rosenstone, 1980). Entretanto, enquanto o alto comparecimento do eleitor é freqüentemente considerado um sinal da saúde política de um país, o status do voto obrigatório no Brasil é precário: os que elaboram políticas, grupos de interesses e partidos regularmente sugerem sua eliminação. Quais são as conseqüências de abolir o voto obrigatório? Este artigo dimensiona as conseqüências em termos da igualdade de participação para grupos políticos e demográficos de eleitores brasileiros.

\section{Uma tipologia de eleitores}

Considerando que podemos pensar sobre indivíduos em termos de suas decisões de participação sob ambas as leis obrigatória e voluntária, uma matriz de subtipos se apresenta. Sob os dois conjuntos de leis, o indivíduo tem três opções: dar um voto válido, abster-se ou dar um voto em branco ou nulo. A Tabela 1 apresenta os nove subtipos que resultam dessas opções.

\section{Tabela 1}

Uma tipologia de eleitores

\begin{tabular}{|c|c|c|c|c|}
\hline \multirow{5}{*}{$\begin{array}{l}\text { Decisão sob leis } \\
\text { de voluntariedade }\end{array}$} & & \multicolumn{3}{|c|}{$\begin{array}{l}\text { Decisão sob leis } \\
\text { obrigatórias }\end{array}$} \\
\hline & & voto válido & abstenção & $\begin{array}{l}\text { voto em branco/voto } \\
\text { nulo }\end{array}$ \\
\hline & voto válido & $\begin{array}{l}\text { (1) participante } \\
\text { compromissado }\end{array}$ & $\begin{array}{l}(2) \\
- \\
-\end{array}$ & (3) \\
\hline & abstenção & (4) participante flexível & $\begin{array}{l}\text { (5) não- } \\
\text { participante } \\
\text { compromissado }\end{array}$ & $\begin{array}{l}\text { (6) não-participante } \\
\text { flexivel }\end{array}$ \\
\hline & $\begin{array}{l}\text { Voto em branco e } \\
\text { nulo }\end{array}$ & $\begin{array}{l}7) \\
-\end{array}$ & $\begin{array}{l}8) \\
-y^{\prime}\end{array}$ & $\begin{array}{l}\text { (9) dissidente } \\
\text { compromissado }\end{array}$ \\
\hline
\end{tabular}


A tabela produz um número interessante de subtipos. O que se pode chamar de resultados puros estão posicionados ao longo da diagonal entre a célula 1 e a célula 9: o participante compromissado, o não-participante compromissado e o dissidente compromissado. Cada um desses indivíduos é imune aos efeitos das leis de comparecimento obrigatório, na medida em que seu comportamento é constante independentemente da lei. As outras células representam indivíduos afetados de algum modo pelas leis eleitorais obrigatórias. As células 4 e 6 contêm indivíduos para quem o voto obrigatório tem seu efeito intencional. Ou seja, o participante flexível e o não-participante flexível representam aqueles cidadãos que não votariam (de forma válida ou não) onde não houvesse $\mathrm{o}$ voto obrigatório. As células restantes contêm indivíduos dos quais 0 comportamento muda com a imposição do voto voluntário de maneira aparentemente irracional ou inconsistente ${ }^{1}$. Esses indivíduos provavelmente existem (ao menos em pequeno número) mas o âmbito de seu comportamento está além do que pretendo explicar.

Na presente análise estou preocupado com as características daqueles nas linhas 1 e 3: ou seja, aqueles que participam sob o voto voluntário (com voto válido ou não-válido). Adicionalmente, fará sentido comparar as características dessa população com aquelas da população votante sob o atual sistema eleitoral obrigatório (colunas 1 e 3). A diferença nas características dessas duas populações representa o efeito do voto obrigatório na composição do eleitorado.

\footnotetext{
${ }^{1}$ Por exemplo, as células 3 e 7 contêm indivíduos que poderiam ser chamados de atores inconsistentes. Sua escolha entre dar um voto válido e não-válido depende da existência de uma lei de obrigatoriedade. As células 2 e 8 contêm indivíduos aos quais denominei libertários praticantes e dissidentes mistos, respectivamente. Seu comportamento é irrelevante para esse estudo.
} 


\section{Medindo a igualdade participativa}

A principal fonte de dados em que me baseio é um survey realizado pelo Instituto Datafolha. Os dados, coletados entre 16 e 18 de agosto de 1994, dois meses antes da eleição presidencial de outubro, compreendem 10.459 eleitores registrados de 256 municípios. A amostra aleatória estratificada cobre todo o Brasil, incluindo as capitais de estado. Também utilizo dados de um survey semelhante realizado antes da eleição de 1998.

A variável dependente à qual me atenho - comparecimento em um cenário voluntário hipotético - não pode ser medida diretamente. Galen Irwin, estudando o contexto holandês em que o voto obrigatório fora abolido em 1970, foi capaz de comparar traços dos eleitores antes e depois daquele ano. No Brasil, contudo, o voto obrigatório existe continuamente desde 1934 e qualquer descrição de um eleitor voluntário deve ser puramente hipotética. Como um indicador, uso a questão: "Se o voto não fosse obrigatório, você votaria?". Admito que essa medida é problemática.

Primeiro, os respondentes aumentam o relato sobre sua história eleitoral ${ }^{2}$. PedirIhes para dizer seu comportamento hipotético é pedir por ainda maior imprecisão. Além disso, as limitações dos dados requerem ao menos dois supostos no sentido de permitir inferências sobre o efeito na eqüidade. Em primeiro lugar, deve-se assumir que os indivíduos registrados pesquisados pelo Datafolha são representativos da população mais ampla. Uma coisa é afirmar que o voto obrigatório produz um comportamento representativo dos eleitores registrados, e outra é argumentar que isso representa os brasileiros. De fato, em termos de igualdade, a questão (obrigatório ou voluntário?) rapidamente torna-se pouco prática se os grupos já foram excluídos no processo de registro. Entretanto, dada a grande porporção de brasileiros registrados, este suposto não parece estar violado.

Em segundo lugar, deve-se assumir que oito entre dez brasileiros que aparecem para votar em eleições obrigatórias são pouco representativos da população mais ampla. Esse suposto é útil porque os dados não nos permitem isolar aqueles que não votam em situações obrigatórias ${ }^{3}$. Se esse suposto é necessário, também é vulnerável ${ }^{4}$.

\footnotetext{
${ }^{2}$ É sabido que respondentes de surveys apresentam-se e expõem seu comportamento aos entrevistadores da forma socialmente desejável.

${ }^{3}$ Não é surpreendente que essa variável não conste dos dados. A questão, de fato, perguntaria se o respondente transgrideria a lei. No sentido de estimar o potencial e as consequências dessa afirmativa, nos voltamos a evidência do comparecimento em um cenário obrigatório. Se esses dados são raros (sobretudo porque envolve perguntar sobre um comportamento ilegal), Lima (1990) mostra evidências usando taxas de comparecimento e a composição demográfica dos estados.

${ }^{4}$ Ver Elkins (1997) para os testes dessas afirmativas.
} 


\section{Eqüidade demográfica}

A análise a seguir detalha o grau de representação entre a população de eleitores voluntários em 1994 e 1998, e também inclui comparações com os Estados Unidos - um caso comparável em muitos aspectos, exceto pela sua longa tradição de voto voluntário.

Tabela 2

Comparecimento voluntário hipotético segundo variáveis demográficas selecionadas.

\begin{tabular}{|c|c|c|c|c|c|}
\hline Atributos & 1994 & 1998 & Atributos & 1994 & 1998 \\
\hline Idade & & & Renda & & \\
\hline 16 e 17 & 42.9 & 33.4 & $<1 \mathrm{SM}$ & 43.9 & 49.0 \\
\hline 18 a 24 & 44.8 & 52.7 & $1>2 \mathrm{SM}$ & 47.1 & 48.6 \\
\hline 25 a 34 & 44.1 & 49.4 & $2>3 \mathrm{SM}$ & 45.7 & 53.9 \\
\hline 35 a 44 & 46.0 & 48.4 & $3>4 \mathrm{SM}$ & 45.2 & 57.7 \\
\hline 45 a 59 & 50.14 & 52.4 & $4>5 \mathrm{SM}$ & 48.1 & 60.4 \\
\hline $60+$ & 60.9 & 60.1 & $>5 \mathrm{SM}$ & 57.4 & 72.0 \\
\hline Raça & & & Residência & & \\
\hline Branco & 47.9 & -- & Rural & 44.3 & -- \\
\hline Mulato & 45.9 & -- & Suburbana & 45.4 & -- \\
\hline Negro & 46.2 & -- & Urbana & 51.6 & -- \\
\hline Asiático & 56.5 & -- & & & \\
\hline Escolaridade & & & Região & & -- \\
\hline Nenhuma & 63.2 & 52.7 & Sudeste & 47.2 & -- \\
\hline Primário & 44.1 & 45.3 & Sul & 49.0 & -- \\
\hline Secundário & 44.2 & 48.6 & Nordeste & 45.7 & -- \\
\hline Superior e mais & 60.4 & 50.1 & Centro-Oeste & 46.7 & \\
\hline
\end{tabular}

Universo: Eleitores registrados

Fonte: Datafolha, 1994; Datafolha, 1998 
Tabela 3

Efeito independente das variáveis demográficas selecionadas sobre o voto voluntário (logit)

\begin{tabular}{|c|c|}
\hline Variável & $\begin{array}{c}\text { Efeito independente com } \\
\text { relação à categoria de } \\
\text { referência }\end{array}$ \\
\hline \multicolumn{2}{|l|}{ Sexo** } \\
\hline Masculino & ---- \\
\hline Feminino & 11.0 \\
\hline \multicolumn{2}{|l|}{ Renda } \\
\hline$<1 \mathrm{SM}$ & ---- \\
\hline 1 a 2 SM & 1.7 \\
\hline 2 a 3 SM & 3.3 \\
\hline 3 a $5 \mathrm{SM}$ & 5.0 \\
\hline 5 a $10 \mathrm{SM}$ & 6.7 \\
\hline $10+S M$ & 8.6 \\
\hline \multicolumn{2}{|l|}{ Idade } \\
\hline 16 a 17 & ---- \\
\hline 18 a 24 & -1.1 \\
\hline 25 а 34 & -2.8 \\
\hline 35 a 44 & -4.9 \\
\hline 45 a 59 & -7.3 \\
\hline $60+$ & -10.6 \\
\hline \multicolumn{2}{|c|}{ Escolaridade ${ }^{* *}$} \\
\hline Nenhuma & ---- \\
\hline Primário & 10.2 \\
\hline Secundário & 20.6 \\
\hline Superior e + & 31.3 \\
\hline \multicolumn{2}{|l|}{ Residência } \\
\hline Rural & ---- \\
\hline Urbana & 4.4 \\
\hline \multicolumn{2}{|l|}{ Raça } \\
\hline Branca & ---- \\
\hline Negra & -2.0 \\
\hline Mulato & 1.5 \\
\hline Asiático & 5.7 \\
\hline
\end{tabular}

Universo: Eleitores registrados

Fonte: Datafolha, 1994

** Significativo a 01

(---) Categoria de Referência

Obs: Esses são coeficientes Logit convertidos em probabilidades. Os valores representam o efeito médio para os indivíduos em cada categoria com respeito à categoria de referência controlado por 15 variáveis politicamente relevantes (ver Anexo A para os coeficientes de regressão e o Anexo B para a descrição do método usado para convertê-los em probabilidades) 


\section{Educação}

O achado de maior demonstração dos estudos sobre participação é o profundo efeito da escolaridade (p.ex., Wolfinger and Rosenstone, 1980). Estudiosos sobre participação concordam amplamente que a educação canaliza seus efeitos de duas formas principais. Primeiro, o aumento da escolaridade afeta um número de variáveis psicológicas - entre elas, eficácia política, interesse político, dever cívico e sofisticação política -, as quais, por sua vez, estão estreitamente associadas com a inclinação do indivíduo em acompanhar a política e engajar-se em participação política. Em segundo lugar, o aumento da escolaridade proporciona habilidades práticas aos cidadãos, que facilitam a negociação das tarefas administrativas necessárias (mesmo mínimas) requeridas aos eleitores. Verba, Schlozman and Brady (1995) especificam essas relações com muita precisão em seu modelo ${ }^{5}$.

Os dados do Datafolha não nos permitem destacar diferenças entre variáveis intervenientes. Uma visão geral inicial nas relações dos dados, entretanto, indica que os mesmos mecanismos causais são apropriados para o contexto brasileiro. Por exemplo, os dados mostram que a porcentagem de brasileiros com algum interesse em política aumenta com o nível educacional.

Dado o forte efeito positivo da escolaridade, as evidências são problemáticas (ver Tabela 2). Tanto os dados de 1994 quanto os de 1998 mostram que conforme se passa do nível primário para o secundário e, finalmente, para os brasileiros de nível superior, o comparecimento aumenta apenas marginalmente. O fenômeno mais notável é a forte participação dos não-escolarizados, e os indivíduos mais participativos são aqueles localizados no fim da escala de escolaridade. O quê poderia possivelmente contar para a natureza super-participativa dos não-escolarizados no Brasil? As explanações mais plausíveis dizem respeito ao status singular dos analfabetos anterior à lei. Devemos lembrar que os analfabetos brasileiros são uma entre muitas categorias não obrigadas a ter registro ou a votar. Segundo indicam os registros da PNAD, um número razoável de analfabetos (que são muitos), escolhem não se registrar (Elkins, 1997). Dado que nossos dados não incluem os não-registrados, é possível que a amostra de analfabetos não seja representativa. Especificamente, é provável que aqueles analfabetos incluídos no survey ou seja, aqueles que se incomodaram em retirar o título de eleitor - sejam mais motivados do que os não-registrados. Logo, não é correto afirmar que o analfabeto é especialmente participativo, mas sim, que os analfabetos registrados são, comparados ao restante da população registrada.

\footnotetext{
${ }^{5}$ Com a publicação do volume de Verba, Schlozman, Brady -e com ele um modelo muito bem especificado - há lugar para algum questionamento sobre o efeito da educação através de habilidades. A análise de regressão sugere que as variáveis spbre envolvimento político fazem a maior parte do trabalho.
} 
O caso do analfabeto hiper-participativo, entretanto, não está resolvido. A metodologia de amostragem é apenas parte da explanação. Há razão para acreditar que o não-escolarizado tem uma maior consideração pela cabine eleitoral do que têm outros brasileiros. A retirada da obrigatoriedade torna a ação mais atrativa, e os respondentes "liberados" podem expressar um disposição maior em engajar-se na atividade do que aqueles que estão sob a obrigatoriedade. De fato, o "efeito de liberdade", se é possível chamar assim, pode ser responsabilizado pelo grau de apatia entre a população em geral. Os brasileiros que afirmam que não votariam em um cenário de voto voluntário podem estar informando, em algum nível, seu "mal-estar" com a obrigatoriedade do voto, e não sua indiferença quanto aos resultados políticos. Os analfabetos podem não sentir esse malestar com a mesma intensidade que os demais.

No sentido de testar essa possibilidade, processei uma regressão do comparecimento voluntário sobre todas as variáveis usuais, assim como também a resposta à pergunta "Você é a favor ou contra o voto obrigatório?" (ver Anexo A.) A última é uma medida direta do mal-estar do indivíduo quanto ao voto obrigatório. Se os não-escolarizados são especialmente participativos devido a seu sentimento positivo quanto ao voto obrigatório, esse novo modelo deveria mostrar um maior efeito positivo para educação. Não surpreendentemente, a variável "mal-estar" teve um efeito substantivo sobre o comparecimento voluntário. De fato, nenhuma outra variável explicativa aproximou-se tanto da predição da participação voluntária como o "mal-estar" com o voto obrigatório. Ainda mais interessante, entretanto, é o amplo, positivo e estatisticamente significativo efeito que a escolaridade apresenta sobre o comparecimento voluntário. Aparentemente, quando se controla a opinião sobre o voto obrigatório, o mistério do não-escolarizado ativo se resolve. A Tabela 3 apresenta os resultados relevantes da regressão logit. A chance de alguém votar em um cenário voluntário aumenta fortemente em 10 pontos percentuais a cada aumento do nível de escolaridade. Por exemplo, em geral, os indivíduos com nível superior votariam a uma taxa $30 \%$ mais alta que os não-escolarizados. Wolfinger e Rosenstone (1980) mostram uma interessante relação entre escolaridade e renda no caso dos Estados Unidos. Os autores encontram que a educação dá um forte aumento aos indivíduos de mais baixa renda do que faz aos de renda mais alta. Os resultados para o voto voluntário divergem desses achados. A Tabela 4 mostra os efeitos médios da educação para os indivíduos, a cada nível de renda e idade.

Assim, se o brasileiro menos rico com nível superior ganha $25.1 \%$ sobre seu correspondente não-escolarizado, o brasileiro mais rico ganha $32 \%$ com a educação superior. Os dados são surpreendentes. Temos toda a razão para esperar efeitos atenuados da escolaridade com grupos que já são mais participativos - embora com renda, isso se dê de forma marginal. Como mostra a Tabela 4, o mesmo fenômeno desviante parece ocorrer com relação à idade. Ou seja, em ambos os contextos brasileiro e norteamericano, o aumento na escolaridade afeta de forma diferente grupos de idade distintos. 
Entretanto, diferentemente dos Estados Unidos, no caso brasileiro é o mais jovem quem obtém mais vantagens pela educação do que o mais velho. Esses desvios do padrão nos Estados Unidos dizem mais respeito às anomalias particulares associadas à idade e renda mencionadas anteriormente.

Tabela 4

Efeito Independente da Educação sobre a Participação Voluntária, por grupos de renda e idade

\begin{tabular}{|c|c|c|c|c|}
\hline & Nenhum & Primário & Secundário & $\begin{array}{c}\text { Universitário e } \\
\text { mais }\end{array}$ \\
\hline Total & ----- & 10.2 & 20.6 & 31.3 \\
\hline \multicolumn{5}{|l|}{ Renda } \\
\hline$<1 \mathrm{sm}$ & ----- & 9.2 & 15.1 & 25.1 \\
\hline 1 a $2 \mathrm{sm}$ & ---- & 10.2 & 20.1 & 28.3 \\
\hline 2 a $3 \mathrm{sm}$ & ---- & 10.2 & 19.9 & 30.7 \\
\hline 3 a $5 \mathrm{sm}$ & ---- & 10.3 & 20.1 & 30.7 \\
\hline 5 a $10 \mathrm{sm}$ & ---- & 10.2 & 20.1 & 31.3 \\
\hline $10+s m$ & ---- & 10.2 & 21.0 & 32.0 \\
\hline \multicolumn{5}{|l|}{ Idade } \\
\hline 16 a 17 & ---- & 10.7 & 20.4 & 34.0 \\
\hline 18 a 24 & ---- & 10.5 & 20.9 & 31.5 \\
\hline 25 a 34 & ---- & 10.2 & 20.5 & 31.6 \\
\hline 35 a 44 & ---- & 10.2 & 20.6 & 31.2 \\
\hline 45 a 59 & ---- & 10.0 & 10.9 & 30.9 \\
\hline $\begin{array}{l}60+ \\
\text { sm=salário mínimo } \\
\text { Universo: Eleitores } \\
\text { Fonte: Datafolha, } 19\end{array}$ & ados & 9.8 & 19.6 & 28.6 \\
\hline
\end{tabular}

Obs. Esses são coeficientes Logit convertidos em probabilidades. Os valores representam o efeito médio para os indivíduos em cada categoria com respeito à categoria de referência controlado por 15 variáveis politicamente relevantes (ver Anexo A para os coeficientes de regressão e o Anexo B para a descrição do método usado para convertê-los em probabilidades) 


\section{Idade}

Muitos estudos mostram que a probabilidade de alguém votar aumenta com a idade até a última década de vida, quando então as taxas de participação caem. Há razão para esperar que o mesmo mecanismo causal opere no Brasil. Primeiro, os brasileiros mais velhos são mais "enraizados" na sociedade e na sua comunidade. São geralmente menos volúveis e tiveram tempo para desenvolver algum grau de conhecimento e opinião sobre temas, candidatos e partidos, que os afetam e à comunidade, assim como são mais propensos a ter vínculos sociais e organizacionais mais fortes.

Segundo, os brasileiros mais velhos são mais propensos a ter mais tempo para acompanhar a política. Ou seja, é mais provável que os mais velhos tenham se desvinculado de suas ocupações e tenham energia disponível para se dedicar a outras causas. Terceiro, voltando à explicação do aumento de atividade entre os escolarizados, é possível que mais velhos tenham um senso maior de "dever cívico". É razoável supor que conforme se envelhece, assume-se mais responsabilidades e papéis adultos. Uma dessas responsabilidades é a participação na política democrática.

Quarto, é possível que essas diferenças quanto a deveres cívicos segundo a idade não seja função do envelhecimento ou de efeitos do ciclo da vida, mas de diferenças entre coortes geracionais. Miller (1992) e Miller and Shanks (1996) argumentam de forma convincente que grupos de eleitores ingressantes na política em diferentes conjunturas na história política dos EUA mostram diferenças notáveis quanto ao seu compromisso com a política. Aqueles pertencentes à geração do New Deal, por exemplo, desenvolveram um padrão de comportamento político distinto das gerações sucessivas ${ }^{6}$. No Brasil, onde historicamente os regimes e ambientes políticos mostraram mais variação do que nos EUA, a probabilidade de haver diferenças profundas nas coortes é muito maior. Entretanto, o efeito exercido pelas práticas eleitorais do regime militar não é inteiramente claro. Teriam as coortes ingressas na política entre 1964 e 1973 (o período mais repressivo) desenvolvido uma inclinação submissa para votar, ou um mal-estar com a manipulação autoritária da democracia? Seriam relutantes em participar?

Os dados brasileiros são muito interessantes. $\mathrm{Na}$ análise bivariada, a idade acompanha a evidência empírica de outros contextos (Miller and Shanks, 1996). Em geral, a probabilidade em votar aumenta com a idade (ver Tabela 2). $\mathrm{O}$ caso brasileiro é apenas anômalo quanto ao fato de que a taxa de participação do conjunto de respondentes mais velhos não declina (de fato, estão sobre-representados).

Entretanto, é concebível que esses achados não contestem diretamente a hipótese de 'queda da última década' por razões similares às discutidas antes sobre os nãoescolarizados. Primeiro, uma vez que os indivíduos não-registrados não são parte de nossa

\footnotetext{
${ }^{6} \mathrm{O}$ efeito de coorte pode aparecer também em uma subpopulação. Wolfinger and Rosenstone (1980) sugerem que diferença no padrão de voto entre mulheres mais velhas e mais jovens tem muita relação com as fortes diferenças na forma em que as mulheres foram socializadas ao longo dos anos.
} 
amostra e, uma vez que, assim como os não-escolarizados, muitos dos brasileiros mais velhos não são registrados, é provável que nossa amostra de brasileiros mais velhos seja sistematicamente diferente de seus semelhantes de fora da amostra.

Segundo, nossa análise inclui uma amplo grupo de indivíduos idosos (60 anos ou mais) e é totalmente possível que existam diferenças dentro dessa população que não estejam evidentes aqui. Na medida em que nossa análise refuta a hipótese da última década, a explanação é semelhante à dos não-escolarizados. Aqueles com mais de 70 anos de idade não são obrigados a votar e, portanto, parecem mais favoráveis ao ato de votar.

A análise multivariada é muito reveladora (ver Tabela 3 e Anexo A). As estimativas Logit não são nem estatística, nem substantivamente significativas. Se há algum efeito da idade, entretanto, ele é negativo - a participação cai uma média de 1.7 pontos percentuais a cada categoria de idade ${ }^{7}$. No sentido de testar o efeito da "queda da última década", o modelo inclui a variável idade ao quadrado. O coeficiente (significativo em muitos dos modelos testados) é levemente positivo, indicando que aqueles que estão nos seus últimos anos não estão se abstendo em grau significativo, mas de fato, estão participando.

A evidência para os eleitores brasileiros voluntários diverge dos achados consagrados sobre os efeitos da idade. De fato, o caso brasileiro vai para um lado, enquanto o caso norte-americano vai para outro. O quê explica essas diferenças? É bem possível, suponho, que os efeitos convencionais do ciclo da vida sublinhados acima realmente existam, mas são cancelados por efeitos concorrentes de coortes. Ou seja, coortes mais velhas crescidas no Brasil autoritário são provavelmente menos participativas em um contexto voluntário do que são as coortes mais jovens crescidas sobre as perspectivas democráticas. O fenômeno no Brasil é o inverso do que Miller e Shanks propõem para o contexto norte-americano. Tais efeitos geracionais podem contribuir para descrever uma ampla variedade de comportamento político em nações em democratização e merece uma análise mais profunda com uma metodologia mais discriminatória. Em nosso caso, é difícil distinguir entre ciclo da vida, coorte e os fatores periódicos que dificultam os estudos geracionais. ${ }^{7}$ É usada a idade real na regressão mas seus resultados são produzidos como médias para as categorias estabelecidas na análise
bivariada. 


\section{Raça}

Por várias razões os resultados quanto aos efeitos da raça deveriam ser os mais esperados. O uso de raça como variável independente afetando a participação política - ou, nesse caso, afetando qualquer indicador social no Brasil- é complicado. Raça começou a ser registrada no censo brasileiro apenas em 1950 e foi omitida pelos censos do governo militar em 1970. Foi apenas na PNAD (Pesquisa Nacional por Amostragem Domiciliar) de 1976 que o governo apresentou os dados de raça nos indicadores sociais, assim como educação e renda. Até 1976, os pesquisadores em ciências sociais quantitativas estavam, como Skidmore (1992) afirma, "desarmados".

A ausência de dados, entretanto, é apenas uma das causas da pesquisa que se baseia na indistinção das cores. Seus defensores trataram o Brasil como uma "democracia racial" sem os ideais de supremacia que inviabilizaram o avanço dos não-brancos em todo lugar. Acadêmicos brasileiros e estrangeiros, assim como a elite brasileira, perpetuaram esse ideal igualitário através de boa parte do século XX (ver Skidmore, 1974 e 1992). Variáveis históricas e geográficas explicavam o baixo nível socioeconômico dos nãobrancos, e a classe social, na mesma direção, explicava o surgimento de todo o preconceito racial.

Visitantes ocasionais e observadores da sociedade brasileira ficavam impressionados com o grau de integração social e aparente liberdade de acesso social e mobilidade dos não-brancos. Theodore Roosevelt, após sua viagem à América do Sul relatou assim: "Se me fosse pedido para indicar um ponto no qual há completa diferença entre os brasileiros e nós mesmos, eu diria que é a atitude com relação ao homem preto... No Brasil, a qualquer negro ou mulato que se apresenta, Ihe é dado, sem questionar, o lugar para o qual suas habilidades qualificam" (citado em Wood e Carvalho, 1988: 135). O mito foi legitimado internacionalmente em 1950 quando a UNESCO iniciou um projeto de pesquisa para investigar a fonte da harmonia racial no Brasil.

Tem sido usual nos últimos 40 anos desbancar o "mito da democracia racial". Florestan Fernandes e a "Escola paulista" deram início com a afirmativa de que o preconceito racial existe sim no Brasil, e seguiram provando que raça é um fator significativo e independente do status social e econômico brasileiro. Fernandes é responsável pela sempre citada frase que os brasileiros mostram "preconceito sem ter preconceito" (Skidmore, 1992). As idéias de Fernandes são compartilhadas por boa parte da população. Uma pesquisa do IBOPE de 1991 mostrava que $83 \%$ dos brancos e $78 \%$ dos pretos concordavam com a afirmação "a discriminação racial existe no Brasil mas poucos admitem". Os dados do censo de 1976 permitiam aos pesquisadores mostrar que, depois de controlados por outras variáveis relevantes, a raça contribuía de fato com o sucesso econômico. 
Dado que a raça isoladamente contribui para o status econômico e social, que efeitos teria sobre a tendência do brasileiro em participar politicamente? Uma hipótese, ao menos, é que os não-brancos mostram um menor grau de eficácia. Ou seja, têm uma estimativa diminuída de sua capacidade para afetar resultados políticos e afetar os políticos para responder suas demandas. O processo político, eles raciocinam, é governado por brancos e para brancos. Por quê votar?

Entretanto, os dados indicam que raça não exerce um papel significativo na participação política no Brasil. As taxas de comparecimento para as três maiores categorias (negro, mulato e branco) são muito equivalentes ${ }^{8}$. Negros, mulatos e brancos são igualmente participativos (ou não-participativos, como eram). Da mesma forma, quando isolados, o efeito independente de raça é próximo de zero (e, de fato, estatisticamente indistinguível de zero). Os efeitos líquidos da cor da pele - não mais do que 3 pontos percentuais para cada grupo - são de fato desconsideráveis.

\section{Tabela 5}

Efeito independente da Raça sobre o Comparecimento Voluntário, por renda e grupos de escolaridade.

\begin{tabular}{llll}
\hline & Branco & Mulato & Negro \\
\hline Total & ---- & 1.47 & -2.03 \\
& & & \\
Renda & & 1.46 & -2.03 \\
< 1 SM & ---- & 1.45 & -2.02 \\
1 a 2 SM & ---- & 1.49 & -2.04 \\
2 a 3 SM & ---- & 1.47 & -2.10 \\
3 a 5 SM & ---- & 1.49 & -2.00 \\
5 a 10 SM & --- & & \\
& & 1.34 & -2.00 \\
Escolaridade & ---- & 1.46 & -1.99 \\
Nenhuma & ---- & 1.51 & -2.13 \\
Primário & ---- & 1.46 & \\
Secundário & --- & & \\
Superior ou + & & &
\end{tabular}

Categoria de Referência (---) Universo: Eleitores registrados Fonte: Datafolha, 1994
Obs. Esses são coeficientes Logit convertidos em probabilidades. Os valores representam o efeito médio para os indivíduos em cada categoria com respeito à categoria de referência controlado por 15 variáveis politicamente relevantes (ver Anexo A para os coeficientes de regressão e o Anexo B para a descrição do método usado para convertê-los em probabilidades)

A ausência de efeitos de raça sobre o voto voluntário é surpreendente em uma sociedade onde se é levado a crer que raça importa. Essa não-representatividade racial afeta outros modos mais ativos de atividade social e política? Uma análise da participação em um conjunto de outras atividades políticas indica que os negros particularmente não estão representados em tipos importantes de participação política (p.ex, membros de

\footnotetext{
${ }^{8}$ IBOPE, 3 de maio, 1991.
} 
partidos políticos), assim como tipos de participação social (p.ex. clubes esportivos e culturais) (Elkins, 1997). Por quê ocorre que um grupo de pessoas marginalizadas em outras atividades voluntárias é bem representado entre eleitores voluntários? O voto considerados os seus custos relativamente baixos- é menos proibitivo para minorias raciais que as outras atividades? O caso norte-americano, ao menos, é discordante dessa explicação (Elkins, 1997). Há algo especial nas eleições brasileiras. Uma explicação é que o voto obrigatório serviu de algum modo para criar normas e hábitos de votar - normas e hábitos que não conseguiram se desenvolver em outras formas de participação.

Além disso, esses dados nos lembram que, apesar do descrédito no mito da democracia racial brasileira nas décadas recentes, o Brasil não é a África do Sul, ou ainda, os EUA. Raça tem aqui muitas nuances e é uma influência significativamente menos polarizadora no Brasil do que em qualquer parte. Discriminação racial e marginalização certamente existem, e têm efeito sobre comportamento político. Entretanto, é provável que a desigualdade racial seja mais significativa em outras arenas da sociedade brasileira do que na arena da participação eleitoral.

\section{Renda}

Muitos estudos sobre participação descrevem os votantes como mais ricos do que os não-votantes ${ }^{8}$. Não é difícil entender as razões dessa relação. Da mesma forma que a educação, renda deveria afetar algumas das mesmas variáveis psicológicas que levam à participação. Os cidadãos mais ricos geralmente têm um senso maior de eficácia. Os mais ricos sentem provavelmente mais que podem afetar o governo e que o governo lhes é responsivo. Outras medidas de engajamento político também seriam afetadas. Wolfinger and Rosenstone (1980) sugerem cinco papéis para a renda (p.20-22):

1.Pessoas desesperadamente pobres estão preocupadas com a luta para manter juntos corpo e alma...

2. Sem considerar sua formação educacional, pessoas com uma vida melhor provavelmente adquirem em seus trabalhos os interesses e as habilidades que conduzem ao envolvimento político e a votar.

3. Mais que escolaridade ou ocupação, renda determina a vizinhança dos indivíduos, e, portanto a exposição a uma variedade de normas e pressões...

4. Alguém com sucesso material, apesar de pouca escolaridade, é provavelmente competente, satisfeito e engajado...

5. Pessoas ricas têm um maior "apego ao sistema" e portanto são mais altamente motivadas a fazer a escolha apropriada nas eleições e apoiar o sistema político, nele participando.

Essas tendências deveriam ser ainda mais dramáticas no Brasil que tem uma tremenda desigualdade de renda e, consequentemente, um significativo grau de 
marginalização. A Tabela 2, entretanto, indica que o comparecimento ao voto voluntário varia muito pouco com a renda. Depois da raça, grupos de renda são os melhor representados dos grupos demográficos. Além disso, esse nível de igualdade contrasta fortemente com a representação desproporcional dos grupos de renda evidente em análises de outras atividades sociais e políticas (Elkins, 1997).

Curiosamente, a maior parte da distorção na representação resulta da hiperatividade no mais alto nível de renda (ver Tabela 2). Em outras palavras, se existe uma elite econômica super -participativa, parece não existir uma classe mais baixa nãoparticipativa.

Esta é uma relação mantida se controlarmos com outras variáveis? A Tabela 6 mostra os efeitos independentes da renda por nível educacional - uma representação que nos permite observar tanto o comportamento de encanadores quanto de bibliotecários ${ }^{9}$. 0 efeito da renda - $2 \%$ para cada aumento - é marginal. Esta relação independente (ou a ausência de uma) acompanha a evidência do contexto norte-americano. Entretanto, em contraste com os achados de Wolfinger and Rosenstone (1980), renda não proporciona um aumento maior para os menos escolarizados do que faz para os mais escolarizados entre os eleitores voluntários no Brasil.

Tabela 6. Efeito Independente da Renda sobre o Comparecimento Voluntário por grupo de escolaridade.

\begin{tabular}{|c|c|c|c|c|c|c|}
\hline \multicolumn{7}{|c|}{ Renda } \\
\hline & $<1 \mathrm{sm}$ & $1<2 \mathrm{sm}$ & $2<3 \mathrm{sm}$ & $3<5 \mathrm{sm}$ & $5<10 \mathrm{sm}$ & $>10 \mathrm{sm}$ \\
\hline Total & ----- & 1.7 & 3.3 & 5.0 & 6.7 & 8.6 \\
\hline \multicolumn{7}{|l|}{ Escolaridade } \\
\hline Nenhuma & ----- & 1.5 & 3.1 & 4.6 & 6.5 & 8.3 \\
\hline Primário & ----- & 1.7 & 3.3 & 4.9 & 6.5 & 8.3 \\
\hline Secundário & ----- & 1.7 & 3.3 & 4.9 & 6.5 & 8.1 \\
\hline Superior ou + & ----- & 1.6 & 3.4 & 5.2 & 6.8 & 8.9 \\
\hline
\end{tabular}

\begin{tabular}{l|l} 
Categoria de referência (---) & $\begin{array}{l}\text { Obs. Esses são coeficientes Logit convertidos em probabilidades. Os valores } \\
\text { sm = salário mínimo }\end{array}$ \\
representam o efeito médio para os indivíduos em cada categoria com respeito à \\
Fonte: Datafolha, 1994 & $\begin{array}{l}\text { categoria de referência controlado por 15 variáveis politicamente relevantes (ver } \\
\text { Anexo A para os coeficientes de regressão e o Anexo B para a descrição do } \\
\text { método usado para convertê-los em probabilidades) }\end{array}$
\end{tabular}

Entretanto, ainda é curioso que a taxa de participação para o brasileiro de mais baixa renda aproxime-se da média da amostra. Por quê os economicamente marginalizados não estão ausentes em grande número, comparados com os grupos mais "incluídos"? Duas explicações se colocam: primeiro, o voto obrigatório e outros instrumentos inclusivos têm institucionalizado, em alguma medida, um hábito de dever cívico. Grupos marginalizados que, de outra forma, estariam ausentes por anos, desenvolveram uma certa inclinação para a participação no cenário obrigatório.

${ }^{9}$ Por ex., Verba and Nie (1972); Wolfinger and Rosenstone (1980). 
A segunda explicação é, de fato, uma versão cínica da primeira. Esta institucionalização da participação deve-se a influências clientelísticas não-democráticas sobre a participação. De acordo com essa perspectiva, grupos de baixa renda votarão em grande número no sentido de assegurar os benefícios reais prometidos pelos eleitos. Dessa forma, não é surpresa que os marginalizados votem, nem deveríamos gostar de sua participação.

Há um substancial terreno comum entre as duas explanações. Ambas concordam que a classe baixa desenvolveu um hábito de votar. A posição mais otimista é que este hábito envolve, em algum nível, um interesse genuíno pela política. A segunda visão e mais pessimista afirma que tal participação é motivada por elementos coercitivos, monopolísticos, endêmicos à política brasileira.

Em que medida o cinismo da segunda visão é justificado? O voto de baixa renda deveria ser desconsiderado como sendo controlado pela elite? A descrição na literatura sobre a peculiaridade de democracia brasileira dá crédito a essa visão. Primeiro, a política no Brasil é decididamente personalista; em muitas áreas, fortes máquinas políticas ainda, controlam eleições. Em segundo lugar, há as práticas de benefício político através de recursos públicos (Ames, 1995). Em terceiro, os muitos partidos são notavelmente frágeis, voláteis e não-representativos (Mainwaring, 1995 ; Power, 1991). Em quarto, as campanhas eleitorais são caras e fortemente dependentes da midia ${ }^{9}$. O cenário resultante é frequentemente associado a relações clientelistas.

Contudo, embora o clientelismo possa ainda descrever a democracia brasileira em algum grau, não é justo considerar o voto dos marginalizados como manipulados pela elite. Primeiro, existe uma esquerda legítima com razoável chance de vencer eleições e, portanto, ser um canal viável para as vozes marginalizadas. Juntamente com o PT, que teve sua força aumentada rapidamente, três outros partidos sustentam a esquerda (PCdoB, PCB e $\mathrm{PSB})^{10}$. Em um campo de partidos fracos e pouco estruturados, esses partidos de esquerda são comparativamente disciplinados e programáticos (Mainwaring, 1995). Esse peso do campo progressista faz aguda oposição ao conservadorismo persistente na política norteamericana. Se Franklin Roosevelt era, como Burnham (1986) apontou, "um liberal em um sistema político que não admitia tais alternativas", Bill Clinton nem pode ser qualificado como tal. Os marginalizados no Brasil, por seu lado, têm na verdade alguém em quem votar.

Uma segunda razão para resistir à crítica clientelista é que o mercado político brasileiro desenvolveu-se de forma inquestionável. Relações que pareciam peculiares ao Brasil (ao menos à América Latina) 40 anos atrás parecem cada vez mais com a política praticada nas democracias ocidentais. Os políticos brasileiros buscam benefícios aos seus eleitores da mesma forma que os membros do Congresso norte-americano fazem. Faz

\footnotetext{
${ }^{10}$ Há um consenso substancial na literatura sobre as características listadas acima. Por exemplo, ver Mainwaring, Power, e Fleischer.
} 
sentido perguntar se o uso do termo "clientelismo" no Brasil hoje significa simplesmente "política responsiva" em outro lugar. Santos (1994), de fato, faz esse questionamento e chama a atenção para que ainda faz sentido considerar a política brasileira em termos de mercado, mas não estamos mais falando de políticos que "trocam votos por sapatos".

Terceiro, cabe dizer que se alguma forma de clientelismo existe, está concentrado na política local onde bens e serviços são alocados de forma mais direta e visível pelos que detêm cargos públicos. Dado que esse estudo concentra-se em eleições presidenciais e congressuais, clientelismo não é tão importante como seria de outra forma.

Isso não significa que relações mercantis não descrevem a política nacional. Ao contrário, Mainwaring (1995) apresenta evidências convincentes de que políticos nacionais dependem dessa manutenção. Entretanto, como seu trabalho demonstra, essa troca de apoio por dinheiro descreve principalmente a relação entre políticos, e não a relação entre político e eleitor.

Em suma, uma vez descartada a interpretação clientelista, não há razão para acreditar que os economicamente marginalizados mostrem níveis surpreendentes de atributos cognitivos que conduzem à participação eleitoral.

\section{Região}

No Brasil, mais que em qualquer país da América Latina, não se pode dar pouca importância às diferenças regionais. Os quase 200 milhões de habitantes estão espalhados em uma área que cobre a maior parte da América do Sul. Redes de comunicação e uma infraestrutura subdesenvolvida limitam a integração, especialmente no Norte. Se por um lado o Brasil moderno não se aproxima da descrição de Robert Wiebes das "comunidades ilhadas" de fins do século 19 nos Estados Unidos, faz muito sentido considerar as regiões como unidades distintas.

Os indicadores socioeconômicos diferem muito segundo a região. Enquanto o nordeste desenvolveu-se rapidamente no Brasil colonial, depois da queda dos preços do açúcar e da ascensão do café e da industrialização, o sudeste tornou-se a terra promissora. Os efeitos sociais dessas diferenças são profundos. A massa de brasileiros do nordeste exibe taxas de alfabetização de mais de $30 \%$ mais baixas que os do sudeste. A diferença é ainda mais dramática quando se considera os números de domicílios servidos por esgotamento, água encanada e eletricidade (Wood e Carvalho, 1988). Culturalmente, as regiões têm se desenvolvido por caminhos díspares, e constituem identidades diversas.

Dadas essas grandes diferenças econômicas e culturais, faz sentido esperar diferenças nas taxas de participação. Os dados de 1994 permitem analisar os respondentes segundo quatro regiões: sudeste, sul, nordeste e centro-oeste. Se considerarmos as regiões isoladamente, não há diferenças regionais para o cenário voluntário (ver Tabela 2). Como sabemos, entretanto, regiões são altamente correlacionadas com status 
socioeconômico e parece correto observar grupos regionais controlados por indicadores socioeconômicos. A análise de regressão sugere que fatores regionais podem ter impacto pouco perceptível sobre a participação, se outros fatores forem controlados. Os do nordeste ganham 6.6 pontos sobre os de outras regiões (Tabela 3). Não está claro, entretanto, o quê pesa para essas diferenças. Parece que as diferenças nas instituições políticas entre estados e regiões têm algum papel.

Entretanto, as regiões brasileiras, como em qualquer lugar, são amplamente distintas por seu grau de urbanização e industrialização. Regiões podem refletir culturas políticas diferentes por outras razões, mas frequentemente tais diferenças podem ser explicadas pelas diferenças entre o rural e o urbano. Cenários rurais, onde os cidadãos não estão convenientemente localizados próximos às urnas, impõem maiores custos de transportes para os eleitores. De fato, o efeito regional diminui quando controlamos como medida a urbanidade do respondente (ver Anexo A e Tabela 3).

\section{Efeitos sobre a política}

Uma coisa é demonstrar diferenças demográficas entre eleitores e não-eleitores; outra coisa é mostrar as diferenças reais nas escolhas políticas. Pode-se argumentar (como faço na conclusão) que um comparecimento representativo é desejável como benefício do voto de larga escala. Entretanto, claramente um dos argumentos para uma amostra representativa de eleitores é que ela sustenta uma agenda de políticas mais descritiva das vontades do eleitorado global. Wolfinger and Rosenstone (1980) demonstram que apesar de desvios demográficos significativos em comparecimento, os interesses nas políticas estão bem representados pelos $50 \%$ do eleitorado norte-americano que comparecem para votar. Que evidência temos do contexto brasileiro? No sentido de descrever as visões políticas dos eleitores voluntários preditos, utilizei três indicadores: filiação político-partidária em 1994 e 1998, escolha do candidato a presidente em 1994 , e opinião sobre o Plano Real em 1994.

O uso da filiação político-partidária apresenta tanto vantagens quanto desvantagens. A multiplicidade de partidos no Brasil permite identificar uma ampla gama de escolhas ideológicas entre os eleitores. Entretanto, algumas das fragilidades da estrutura partidária não nos permite esboçar conclusões de longo alcance sobre esse indicador. Primeiro, o sistema eleitoral é altamente personalista e os eleitores identificam-se mais com candidatos do que com partidos. Segundo, exceto para a esquerda, os partidos não são altamente ideológicos. Os candidatos transferem suas lealdades para partidos contrários sem sacrificar muito de sua agenda política. Terceiro, partidos são notavelmente indisciplinados. Consequentemente, votar em um membro de um partido não necessariamente significa um voto nas políticas defendidas pelo partido. Apesar desses 
problemas, entretanto, uma olhada nas taxas preditas de comparecimento por partido (Tabela 7) é um indicador útil de representação política no cenário voluntário.

Os respondentes alinhados com os partidos mais conservadores são levemente mais participativos.

Tabela 7

Comparecimento voluntário predito por identificados com partidos políticos.

\begin{tabular}{lrr}
\hline Preferência Partidária & $\begin{array}{c}\text { Comparecimento } \\
\text { hipotético-1994 (\%) }\end{array}$ & $\begin{array}{c}\text { Comparecimento } \\
\text { hipotético-1998 (\%) }\end{array}$ \\
\hline Esquerda & 51.3 & 56.7 \\
PT & 56.5 & 67.9 \\
PSB & & \\
Centro & 53.2 & 55.1 \\
PDT & 61.4 & 67.6 \\
PSDB & 47.9 & 54.4 \\
PMDB & 54.1 & 63.3 \\
PTB & & \\
Direita & 64.3 & 62.1 \\
PL & 58.1 & 62.8 \\
PFL & 55.8 & 67.9 \\
PDS & 56.3 & 44.8 \\
PPR & 44.0 & \\
Sem filiação & & \\
* não perguntado em 1998 & & \\
Universo: Eleitores registrados & &
\end{tabular}

Dado que partidos não são necessariamente indicativos de escolhas políticas, o que podemos dizer sobre as preferências por candidatos e políticas específicos? A Tabela 8 apresenta o resultado predito da eleição presidencial de 1994, assim como a opinião sobre o Plano Real com uma amostra voluntária e uma amostra obrigatória.

Tabela 8

Resultados Eleitorais Preditos em Cenários Obrigatório e Voluntário (1994) ${ }^{11}$

\begin{tabular}{lcr}
\hline $\begin{array}{c}\text { Candidatol } \\
\text { posição }\end{array}$ & $\begin{array}{c}\text { Resultados Obrigatórios } \\
\text { (\%) }\end{array}$ & \multicolumn{2}{c}{$\begin{array}{c}\text { Resultados } \\
\text { Voluntários (\%) }\end{array}$} \\
\hline Cardoso & 60.9 & 62.6 \\
Lula & 39.1 & 37.4 \\
\hline $\begin{array}{l}\text { Pro Plano } \\
\text { Real } \\
\text { Anti- Plano }\end{array}$ & 89.7 & 91.4 \\
Real & 10.3 & 8.6 \\
\hline
\end{tabular}

Universo: Eleitores registrados

Fonte: Datafolha, 1994

\footnotetext{
${ }^{11}$ Como especifiquei, os resultados para situação obrigatória são preditos . Utilizo esses resultados preditos da amostra do Datafolha e não os resultados reais, no sentido de manter a comparabilidade com o resultado predito voluntário.
} 
De forma geral, líderes conservadores são os mais relutantes para sustentar métodos de aumento da participação. ${ }^{12}$ As Tabelas 7 e 8 demonstram que elementos conservadores no Brasil se beneficiariam em alguma medida em um cenário voluntário. Claramente, entretanto, o voto obrigatório não está mobilizando a massa de progressistas silenciosos. Em um cenário voluntário, a margem de vitória de $\mathrm{FHC}$ sobre Lula teria apenas crescido três pontos percentuais - um volume que não afetaria a eleição presidencial. Mesmo nas eleições congressuais, nas quais - sob o sistema proporcional brasileiro de lista aberta- votos contam muito mais, essas diferenças seriam apenas marginais.

Certamente é possível que em uma eleição presidencial que legitimasse um candidato de direita, ao invés de um de centro como $\mathrm{FHC}$, as diferenças seriam mais significativas entre os dois cenários.

Analisando a eleição de 1994, o futuro do Plano Real era a questão política mais tratada. Apenas a esquerda trazia elementos políticos que se opunham ao Plano, e mesmo assim, de forma muito dividida. A grande maioria dos eleitores 'obrigados' eram a favor do Plano, em uma proporção que, como mostra a Tabela 8, apenas cresce levemente sob circunstâncias voluntárias. Em resumo, é improvável que qualquer partido, candidato ou grupo de interesse tenha vantagens significativas com o voto obrigatório. Entretanto, como esperado, políticas e grupos conservadores se beneficiariam - mas apenas marginalmente - com uma mudança para o voto voluntário.

\section{Conclusão: implicações para a democracia no Brasil}

As evidências apontam para ao menos três conclusões. Primeiro, é claro que o voto obrigatório aumenta a representação de várias características demográficas importantes. Segundo, entretanto, a extensão dessa melhora em eqüidade não é extraordinariamente ampla, tanto se considerada de forma isolada, quanto com respeito a níveis de representação em outras atividades no Brasil e o voto nos Estados Unidos.

Terceiro, padrões de votação em cenários voluntários hipotéticos diferem daqueles de outros contextos, particularmente os Estados Unidos. Além disso, alguns desses padrões desviantes podem antes serem atribuídos ao efeito das normas institucionalizadas da participação obrigatória.

\footnotetext{
${ }^{12}$ Sendo que o survey foi realizado antes da eleição geral e do enfrentamento entre FHC e Lula, o Datafolha perguntou pelas preferências dadas as possibilidades.
} 
Dados esses achados, o quê podemos dizer sobre o valor do voto obrigatório? Em particular, por quê deveríamos nos preocupar com aumentos de eqüidade, se são aumentos marginais? Vários argumentos se colocam. Primeiro, se pessoas de todas as faixas estão representadas, parece correto afirmar que uma ampla gama de interesses estarão representados entre os líderes eleitos. Esse argumento perde parte de sua força se determinamos que se a ineqüidade pode existir demograficamente em situações voluntárias, ela não aparece em medidas de opinião política. Segundo, pode-se argumentar que a preocupação quanto a representar interesses de um grupo não chega ao ponto grupos e não interesses necessitam ser representados. De acordo com esse argumento, grupos deveriam ser representados porque políticos oferecem benefícios (ou rendimentos, em termos econômicos) aos eleitores. Grupos que não votam não estarão em posição inferior para competir por esses benefícios.

Tenho argumentado que esse tipo de política de troca, se é intrínseca ao governo brasileiro há muitos anos, não é preponderante hoje. Argumentos de eqüidade, então, necessitam avançar por outros terrenos. Há uma terceira e convincente razão para insistir na eqüidade na participação. Essencialmente, ter mais pessoas participando especialmente aquelas que de outra forma se absteriam- ajuda a estimular atitudes e habilidades cívicas, que são importantes de várias maneiras para a qualidade global da democracia.

A avaliação dessa hipótese - $\mathrm{o}$ ato de votar proporciona valiosas habilidades e atitudes - é o próximo passo lógico nessa análise. Há alguma razão para esperar -como Rousseau e Mill esperavam- que haja alguma verdade nessa relação. Por exemplo, um dos achados consistentes de Verba, Schlozman, Brady (1995) é que participantes em uma atividade ganham habilidades cívicas e um senso de engajamento que leva a à participação em outras atividades. Além disso, evidências sugerem que esse efeito educativo e de engajamento é ainda obtido simplesmente perguntando às pessoas sobre política.

Warren Miller mostrou que respondentes ao National Election Studies, selecionados aleatoriamente, votam em taxas mais altas na eleição seguinte à entrevista do que os nãoentrevistados. Miller chama esses surveys de " a forma mais cara de educação cívica conhecida pela humanidade" (citado em Lijphart 1995). Além disso, há evidência no contexto brasileiro para sustentar a associação entre eficácia e eleições. José Álvaro Moisés, estudando a eleição de 1989 em São Paulo, encontrou que enquanto apenas $30.6 \%$ dos respondentes acreditavam em setembro daquele ano que tinham influência na política, três meses depois da campanha e da eleição esse número aumentou para $46.1 \%$. Em outras palavras, a exposição à informação política e o ato de votar podem ter aumentado em $50 \%$ o número de cidadãos com algum grau de eficácia, um atributo que é 
bem conhecido por aumentar a participação. Esse fenômeno é intrigante e merece maior estudo $^{13}$.

Se a evidência sustenta a hipótese que votar traz efeitos positivos sobre a eficácia política, interesse político e sofisticação política, as implicações para o voto obrigatório são profundas. Fazer votar pode bem significar, com efeito, encorajar indivíduos marginalizados a propor idéias, definir políticos responsivos, e buscar fazer diferença na forma como o governo funciona. Em uma sociedade como a brasileira, onde existem níveis extraordinariamente altos de desigualdade e onde a transição para a democracia não está completada, tal catalisador é altamente desejável.

\footnotetext{
${ }^{13}$ Com o objetivo de testar a hipótese para uso nesse estudo, observei dois estudos de painel - um nos Estados Unidos (NES, 1990-94) e na Holanda (DES, 1970-73) onde o voto obrigatório foi eliminado em 1971. Utilizei um desenho simples de préteste/pós-teste para calcular aumentos em eficácia, sofisticação política e interesse político associados ao ato de votar. Se análises mais sofisticadas são claramente necessárias para eliminar outras explicações, os resultados sugerem que eleitores refletem níveis aumentados dessas três variáveis.
} 


\section{Anexo A}

Resultados da Regressão Multivariada

\begin{tabular}{lllllll}
\hline \multicolumn{5}{c}{ Estimativas OLS } \\
Vodelo 1 & \multicolumn{3}{c}{ Modelo 2 } & \multicolumn{2}{l}{ Modelo 3 } \\
Variável & B & SE & B & SE & B & SE \\
\hline Sexo & 0.08 & 0.02 & & & $0.11^{* *}$ & 0.03 \\
Idade & -0.01 & 0.01 & & & 0.00 & 0.01 \\
Idade & 0.00 & 0.00 & & & 0.00 & 0.00 \\
Educação & 0.03 & 0.02 & & & $0.11^{* *}$ & 0.02 \\
Renda & 0.01 & 0.01 & & & 0.02 & 0.01 \\
Negro & 0.00 & 0.04 & & & -0.02 & 0.05 \\
Mulato & 0.01 & 0.03 & & & 0.01 & 0.03 \\
Asiático & 0.07 & 0.14 & & & 0.05 & 0.15 \\
Sul & $-0.13^{* *}$ & 0.03 & & & 0.03 & 0.04 \\
Nordeste & $0.10^{* *}$ & 0.03 & & & $0.07^{*}$ & 0.03 \\
Centro-oeste & 0.01 & 0.04 & & & -0.01 & 0.04 \\
Urbano & $0.08^{* *}$ & 0.03 & & & 0.04 & 0.03 \\
FHC & & & 0.03 & 0.03 & 0.02 & 0.03 \\
Pro Plano Real & & & 0.01 & 0.05 & 0.01 & 0.05 \\
Pro Voto Obrigatório & & & $0.30^{* *}$ & 0.03 & 0.33 & $0.03^{* *}$ \\
PIB & & & $0.09^{* *}$ & 0.04 & 0.08 & 0.04 \\
PMDB & & & -0.06 & 0.05 & -0.04 & $0.05^{*}$ \\
PT & & & 0.00 & 0.05 & 0.00 & 0.05 \\
PSDB & & & 0.02 & 0.05 & 0.01 & 0.06 \\
Engajamento Político & & & $0.04^{* *}$ & 0.01 & $0.04^{* *}$ & 0.01 \\
(Constante) & $0.28^{* *}$ & 0.11 & $0.28^{* *}$ & 0.05 & -0.17 & 0.14 \\
& & & & & & \\
R & & & 0.12 & & 0.16 & \\
SE & 0.03 & & 0.47 & & 0.46 & \\
* Significativo a .05 & & & & & & \\
** Significativo a .01 & & & & & & \\
\hline & & & & & &
\end{tabular}


Estimativas Logit

\begin{tabular}{|c|c|c|c|c|c|c|}
\hline \multirow[b]{2}{*}{ Variáveis } & \multicolumn{2}{|c|}{ Modelo 1} & \multicolumn{2}{|c|}{ Modelo 2} & \multicolumn{2}{|c|}{ Modelo 3} \\
\hline & B & SE & B & SE & B & SE \\
\hline Sexo & $0.34^{* *}$ & 0.09 & & & $0.53^{* *}$ & 0.12 \\
\hline Idade Age & -0.02 & 0.02 & & & -0.01 & 0.028 \\
\hline Idade $^{2}$ & $<.01^{*}$ & $<.01$ & & & $<.01$ & $<.01$ \\
\hline Educação & $0.13^{*}$ & 0.07 & & & $0.51^{* *}$ & 0.1 \\
\hline Renda & 0.05 & 0.04 & & & 0.08 & 0.06 \\
\hline Negro & $<.01$ & 0.18 & & & -0.1 & 0.25 \\
\hline Mulato & 0.05 & 0.11 & & & 0.07 & 0.15 \\
\hline Asiático & 0.27 & 0.57 & & & 0.29 & 0.79 \\
\hline Sul & 0.07 & 0.13 & & & 0.15 & 0.18 \\
\hline Nordeste & $0.39^{* *}$ & 0.12 & & & $0.31^{*}$ & 0.17 \\
\hline Centro-oeste & 0.05 & 0.15 & & & -0.06 & 0.19 \\
\hline Urbano & $0.33^{* *}$ & 0.11 & & & 0.21 & 0.15 \\
\hline $\mathrm{FHC}$ & & & 0.11 & 0.14 & 0.1 & 0.15 \\
\hline Pro Plano Real & & & 0.04 & 0.21 & 0.06 & 0.23 \\
\hline Pro voto obrigatório & & & 1.29 & 0.12 & $1.48^{* *}$ & 0.13 \\
\hline $\mathrm{PIB}$ & & & 0.42 & 0.18 & $0.37^{*}$ & 0.2 \\
\hline PMDB & & & -0.27 & 0.21 & -0.22 & 0.23 \\
\hline PT & & & -0.02 & 0.23 & -0.02 & 0.25 \\
\hline PSDB & & & 0.07 & 0.25 & 0.03 & 0.27 \\
\hline Engajamento Político & & & 0.17 & 0.04 & $0.17^{* *}$ & 0.04 \\
\hline (Constante) & $-.88^{* *}$ & 0.45 & $-0.95^{\star *}$ & 0.22 & $-3.10^{* *}$ & 0.65 \\
\hline $\mathrm{N}$ & 8427 & & 6215 & & 5580 & \\
\hline$\%$ de casos preditos corretamente & 56.53 & & 65.29 & & 68.04 & \\
\hline-2 vezes log likelihood ratio & 2660.72 & & 1837.13 & & 1583.98 & \\
\hline DF & 13 & & 8 & & 21 & \\
\hline
\end{tabular}

* Significativo a .05

** Significativo a .01 


\section{Anexo B}

\section{Método para Conversão das Estimativas Logit}

Usando as estimativas de uma regressão logística no modelo 3 (ver anexo A), primeiro calculei a probabilidade do comparecimento voluntário para cada um dos 10.000 respondentes da amostra. Em seguida calculei uma probabilidade adicional para cada variável de interesse definindo a respectiva variável no seu menor valor. As diferenças entre a primeira probabilidade e a de cada uma das outras representa o efeito da característica dos indivíduos com o comparecimento voluntário com respeito ao mais baixo valor. Por exemplo, no caso da educação, fixei o valor da variável educação em 1 (o código para "sem escolaridade") no cálculo da "segunda" probabilidade. Ao subtrair a equação dois da equação um para cada respondente obtém-se uma estimativa do efeito escolaridade com respeito aos não escolarizados. Das estimativas de cada nível de escolaridade foi tirada a média para chegar ao efeito médio de cada aumento em escolaridade. Essas médias, certamente podem também ser calculadas para grupos diferentes. Por exemplo, na secção sobre escolaridade calculei o efeito médio do nível de escolaridade para cada grupo de renda. 


\section{BIBLIOGRAFIA}

ABRAHAM, H. (1955) Compulsory Voting. Washington, D.C.: Public Affairs Press.

AMES, Barry. (1995) Electoral Strategy under Open-List Proportional Representation. American Journal of Political Science, 39(2):406-33.

BOLLEN, Kenneth A. (1980) Issues in the Comparative Measurement of Political Democracy. American Sociological Review, 45:370-390.

(1990) Political Democracy: Conceptual and Measurement Traps. Studies in Comparative International Development, 25:7-24.

BURNHAM, Walter Dean. (1987) The Turnout Problem. In: REICHLEY, A. James. (ed.) Elections American Style. Washington, D.C., Brookings Institution, p. 97-133.

FIGUEIREDO, Marcus. (1990) O voto obrigatório (comportamento do eleitor brasileiro). Cem anos de eleições presidenciais, Textos IDESP, no. 36, São Paulo: Instituto de Estudos Econômicos, Sociais e Políticos de São Paulo. . (1991) A decisão do voto. São Paulo, Editora Sumaré.

Folha de São Paulo. (1994) "Revisão mantém voto obrigatório", 15 de março:1 e 1-10.

FREYRE, Gilberto. (1956) The Masters and the Slaves (Casa Grande e Senzala): a Study in the Development of Brazilian Civilization. New York, Knopf.

HAGOPIAN, Frances and MAINWARING, Scott. (1987) Democracy in Brazil: Problems and Prospects. World Policy Journal, 485-514.

HASEN, Richard L. (1996) Voting Without Law? University of Pennsylvania Law Review, 144(5).

HIRCZY, Wolfgang. (1994) The Impact of Mandatory Voting Laws on Turnout: A QuasiExperimental approach. Electoral Studies, 13: 64-76.

HUNTINGTON, Samuel P. and NELSON, Joan M. (1976) No Easy Choice: Political Participation in Developing Countries. Cambridge, MA, Harvard University Press.

IRWIN, Galen. (1974) Compulsory Voting Legislation in the Netherlands: Impact on Voter Turnout. Comparative Political Studies, 7:292-315.

JACKMAN, Robert W. (1987) Political Institutions and Voter Turnout in the Industrial Democracies. American Political Science Review, 81:405-23.

KAHN, Tulio. (1992) O Voto Obrigatório. Dissertação de Mestrado. São Paulo, Universidade de São Paulo.

KLEPPNER, Paul. (1982) Who Voted? The Dynamics of Electoral Turnout, 1870-1980. New York, Praeger.

LAMOUNIER, Bolivar and SOUZA, Amaury de. (1993) Changing Attitudes Toward Democracy and Institutional Reform in Brazil. In: DIAMOND, Larry (ed.) Political Culture and Democracy in Developing Countires, Boulder, CO, Lynne Rienner, p.295-326.

LAMOUNIER, Bolivar. (1989) Authoritarian Brazil Revisited: The Impact of Elections on the Abertura. In: STEPAN, Alfred (org.) Democratizing Brazil, New York, Oxford University Press, p.43-79.

LAVAREDA, Jose Antonio. (1991) A democracia nas urnas: o processo partidário eleitoral brasileiro. Rio de Janeiro, Rio Fundo Editora. 
LIMA JUNIOR, Olavo Brasil de. (1983) Electoral Participation in Brazil (1945-1978): the Legislation, the Party Systems and Electoral Turnouts, Luzo-Brazilian Review, 20,1.

(1990) Alienação eleitoral e seus determinantes: nota de pesquisa. Revista Brasileira de Ciências Sociais, 14:68-72.

LIJPHART, Arend. (1994) Democracies: Forms, Performance, and Constitutional Engineering. European Journal of Political Research, 25(1):1-17.

(1997) Unequal Participation: Democracy's Unresolved Dilemma. American Political Science Review, 91(1):1-14.

(1995) Civic Politics and Democratic Institutions: a Plea for the (re-) introduction of Compulsory Voting. In: WISSENBURG, M.L.J. (org.) Civic Politics and Civil Society Proceedings, The Netherlands, University of Nijmegen.

MAINWARING, Scott. (1991) Politicians, parties, and Electoral Systems: Brazil in Comparative Perspective. Comparative Politics, 24: 21-43.

(1993) Brazilian Party Underdevelopment in Comparative Perspective. Political Science Quarterly, 107: 677-708.

(1995) Brazil: Weak Parties, Feckless Democracy. In: MAINWARING, Scott and SCULLY, Timothy R. (orgs.) Building Democratic Institutions: Party Systems in Latin America, Stanford, CA, Stanford University Press, p.354-98.

MILLER, Warren E. (1996) And J. Merrill Shanks. The New American Voter. Cambridge, MA, Harvard University Press.

MOISÉS, José Álvaro. (1993) Elections, Political Parties, and Political Culture in Brazil: Changes and Continuities. Journal of Latin American Studies, 25:575-611.

MYERS, David J. and O'CONNOR, Robert E. (1983) The Undecided Voter in Mandatory Voting Settings: A Venezuelan Exploration. Western Political Quarterly, 36:420-33.

Opinão Publica (1993) I (0)

POWELL, G. Bingham. (1986) American Voter Turnout in Comparative Perspective. American Political Science Review , 80:17-43.

POWER, Timothy J. (1991) Politicized Democracy: Competition, Institutions, and 'Civic Fatigue' in Brazil. Journal of Interamerican Studies and World Affairs, 33:75-112.

POWER, Timothy J. and ROBERTS, J. Timmons. (1995) Compulsory Voting, Invalid Ballots, and Abstention in Brazil. Political Research Quarterly, 48(3):795-826.

REIS, Antonio Carlos Alkmim dos. (1991) A participacão eleitoral e seus correlatos socioeconômicos. In: LIMA JUNIOR, Olavo Brasil de. (org.) Sistema eleitroral brasileiro: teoria e prática. Rio de Janeiro, IUPERJ-Rio Fundo Editora.

ROSENSTONE, Steven J. and HANSEN, John Mark. (1993) Mobililization, Participation, and Democracy in America. New York, Macmillan.

SANTOS, Wanderley Guilherme dos. (1987) Crise e castigo: partidos e gernerais na política brasileira. São Paulo, Vertice.

(1979) Cidadania e justiça. Rio de Janeiro, Campus.

Oligárquico, Rio de Janeiro. (1994) Regresso: Máscaras Institutionais do Liberalismo 
SKIDMORE, Thomas. (1974) Black into White: Race and Nationality in Brazilian Thought. New York, Oxford University Press.

(1992) Fact and Myth: Discovering a Racial Problem in Brazil. Working Paper, the Helen Kellogg Institute for International Studies, University of Notre Dame.

SOARES, Glaucio Ary Dillon and D'ARAUJO, Maria Celina. (1991) Los mitos de la prensa y los votos en las elecciones de 1990. Revista de Estudios Políticos, 74:277-96.

TEXEIRA, Ruy A. (1992) The Disappearing American Voter. Washington, D.C., The Brookings Institution.

VERBA, Sidney and NIE, Norman H.. (1972) Participation in America: Political Democracy and Social Equality. New York, Harper \& Row.

VERBA, Sidney, NIE, Norman and KIM, Jae-on. (1978) Participation and Political Equality: A Seven Nation Comparison. Cambridge University Press.

VERBA, Sidney, BRADY, Henry and SCHOLZMAN, Kay. (1995) Voice and Equality: Civic Volunteerism in American Politics. Cambridge MA, Harvard University Press. (1995) Beyond SES: A Resource Model of Political Participation. American Political Science Review, 89(2):271-94.

WOLFINGER, Raymond E. and ROSENSTONE, Steven J. (1980) Who Votes? New Haven, Yale University Press.

WOOD, Charles H. and CARVALHO, Jose Alberto Magno de. (1988) The Demography of Inequality in Brazil. Cambridge, Cambridge University Press. 